\title{
A cultura liberta
}

Renato Janine Ribeiro

A cultura pode ser encarada como sinônimo de erudição, retratando as oportunidades de acesso a informações e saberes que os sujeitos têm ao longo de sua trajetória de vida ou, como propõe o autor do presente artigo, como experiência que pode ser vivida em diferentes dimensões - ética, política e econômica - que relaciona cultura à ampliação da liberdade e criação de novas formas de vida. 0 autor discorre sobre alguns exemplos de experiência cultural, relacionando-os a diferentes modos de ampliação de horizontes. Conclui afirmando a necessidade de maior organização dos setores que trabalham com a criação cultural e sugerindo a ligação entre cultura e justiça social, de modo a transformar a cultura numa experiência libertária capaz de reduzir as desigualdades sociais.

Palavras-chave: cultura; desigualdades sociais; política 


\section{Culture is freedom}

Renato Janine Ribeiro

Culture can be taken as a synonym for erudition, portraying the opportunities of access to information and knowledge that the individuals have along their life or, as the author proposes, as an experience that may be lived in different dimensions - ethical, political and economic - that relates culture to the expansion of freedom and creation of new forms of life. The author approaches some examples of cultural experience, relating them to different forms of expansion of horizons. He concludes by asserting the need for higher organization of the sectors that work with the cultural creation and suggesting the connection between culture and social justice, so as to transform culture into a libertarian experience capable of reducing social inequalities.

key words: culture; social inequalities; policy 


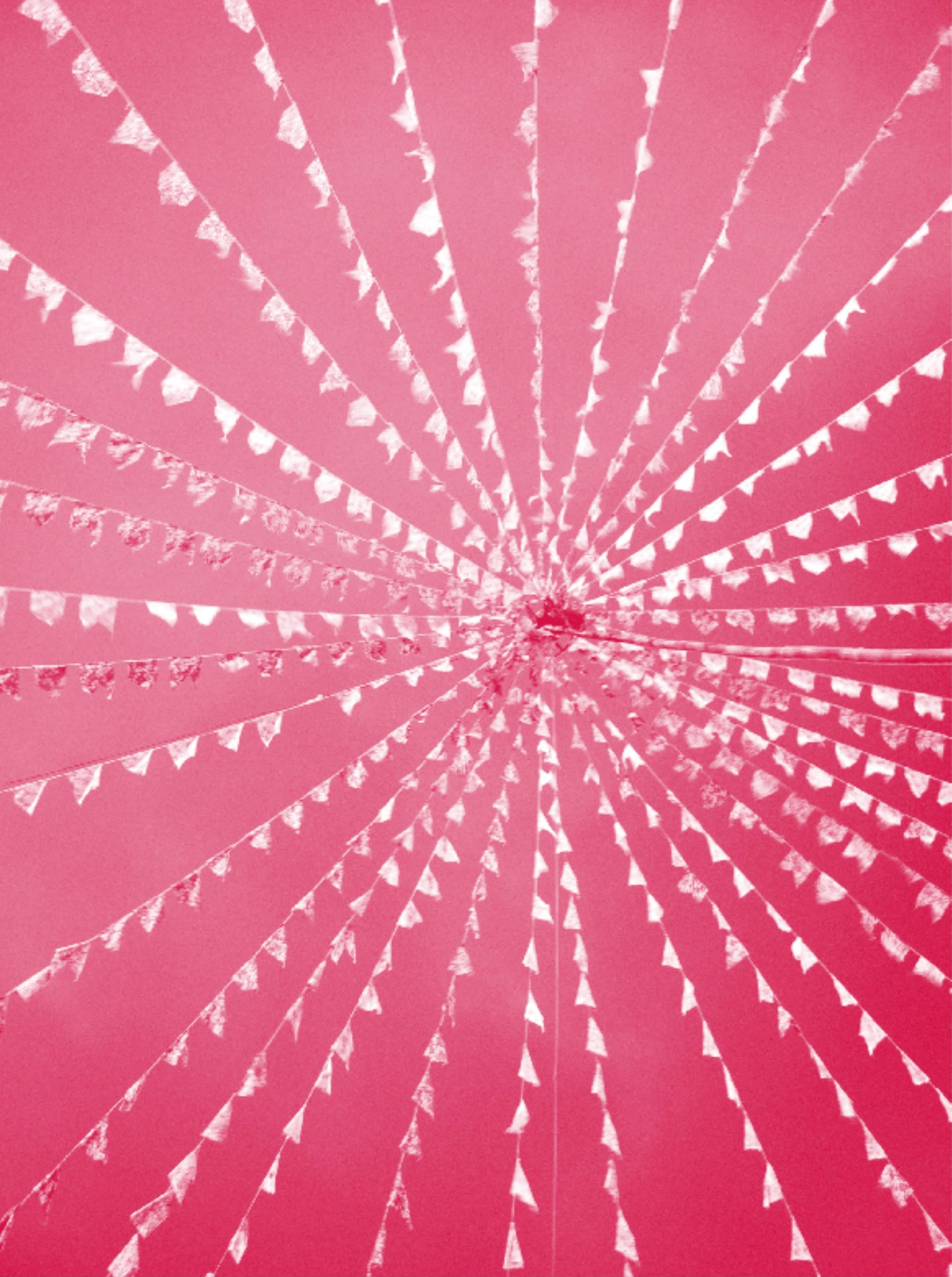




\section{A cultura liberta}

\section{A cultura como experiência}

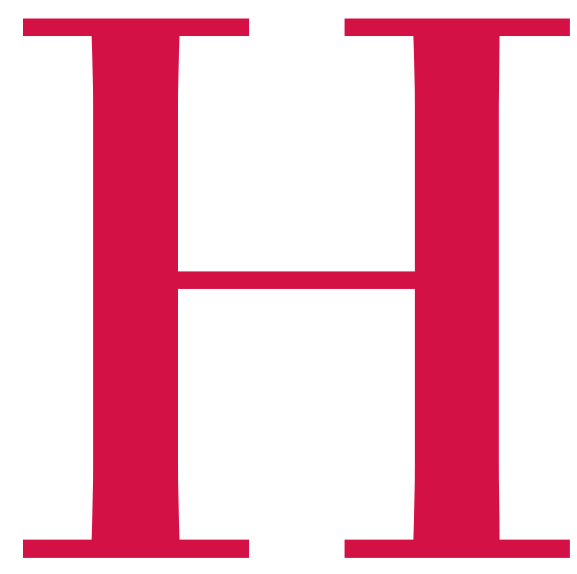

á várias maneiras de pensarmos a cultura. A maior parte das pessoas tende a considerar que a cultura consiste em obras importantes: podem ser obras de arte, de literatura ou filmes, mas elas se caracterizam por se destacarem. Acreditam que a cultura esteja ligada a pessoas cultas, que tiveram acesso a mais informações e, portanto, têm cabedal maior de saberes, de instrução e acesso ao mundo do conhecimento.

Não nego a questão da qualidade - ao contrário! Mas gosto de pensar de um modo não tanto diferente, mas adicional: prefiro correlacionar cultura e experiência. Penso mais em termos de experiência cultural do que em cultura como se esta fosse uma substância.

Ora, o que a experiência cultural traz? Por que, quanto mais obras culturais alguém conhece, parece que menos novas experiências culturais ela vai sentir?

Tem-se por vezes a impressão de que essa pessoa já está bastante enriquecida e que o novo não vai lhe causar uma impressão tão forte quanto alguma que já teve anteriormente. Assim, no filme de Ingmar Bergman, A Flauta Mágica, me chama a atenção um rosto de menina, pré-adolescente, que vai sentindo com intensidade cada episódio da narrativa.

Ela certamente ignora os matizes do canto lírico. Talvez não faça diferença, para ela, se a orquestra é a meIhor do mundo ou uma apenas correta. Mas, de seu olhar, depreendemos que sua experiência é inesquecível, que

* Renato Janine Ribeiro é filósofo e professor-titular da cadeira de Ética e Filosofia Política da Faculdade de Filosofia, Letras e Ciências Humanas da Universidade de São Paulo - FFLCH-USP. Recebeu o Prêmio Jabuti em 2001, na categoria Ensaios e Ciências Humanas, com o livro A Sociedade contra o Social: o alto custo da vida pública no Brasil (2000). Foi condecorado com a Ordem Nacional do Mérito Científico, em 1998, e com a Ordem de Rio Branco, em 2009.

FOTO À ESQ.: III ENCONTRO DE CULTURA CAIPIRA, CDC TIDE SETUBAL, 2009. AUTORIA: VERÔNICA MANEVY. 
ela está descobrindo um campo novo de arte, que está sentindo a arte como se tudo o que se está narrando (o drama de Tamino, Pamina, a Rainha da Noite, Sarastro...) fosse verdade: eis uma experiência cultural forte, e que pode ser maior se a obra for melhor, mas também pode ser autônoma em relação à qualidade da obra.

Outro episódio é o de um filme cubano do começo do período revolucionário. Principiam os anos 1960. Uma aldeia que nunca viu uma tela, um projetor, um filme, vai ter sua primeira experiência com o cinema - e essa experiência é filmada. É um olhar virgem que se abre para experiências novas.

Assim, à medida que uma pessoa vai tendo mais contato com as diversas formas culturais, não apenas ela terá mais dificuldade de se deparar com novidades, como o novo talvez já não cause aquele impacto fabuloso, que nos marca, quem sabe, em definitivo.

Esse é um ponto importante porque, se, por um lado, a questão da cultura é indissolúvel da qualidade, por outro, a experiência cultural pode ser forte ou fraca sem tanta relação com a qualidade da obra, e sim, com a situação do sujeito que a vivencia. Numa primeira abordagem, diríamos que, num caso, se privilegia o objeto e uma visão de qualidade, por isso mesmo, mais “objetiva” (por difícil que seja sustentar isso); e, no outro, se destaca o sujeito, e daí, uma compreensão mais "subjetiva" do que é o papel da cultura na vida das pessoas.

Gosto dessa idéia da cultura abrindo uma experiência cultural que amplia os horizontes das pessoas. Isso lhes proporciona mais liberdade.

Isso não quer dizer que a obra cultural que abre mais horizontes seja necessariamente a melhor, seja uma obra do cânone, a mais conhecida, mais famosa. Para uma pessoa, o que pode abrir o espírito pode ser uma obra não tão boa, mas que, naquele momento, a sensibiliza de tal maneira que provoca uma mudança.

Um exemplo da cultura enquanto experiência que amplia nossa liberdade diz respeito à Irlanda do Sul. Nesse país altamente católico, não se falava de homossexualismo, nem masculino nem feminino. Sublimava-se essa opção sexual. Não sabiam nomear um rapaz que não sentisse atração por mulheres, mas eventualmente se sentisse atraído por homens. 0 jovem nessas condições sentiria que tinha uma vocação para o sacerdócio. Não desejar mulheres não era repertoriado, culturalmente, como desejar homens. 0 rapaz era encaminhado para o clero.
O resultado disso foi terrivel: muitos homossexuais reprimidos se tornaram padres incumbidos de educar crianças pequenas, sobretudo meninos. Disso, decorreu muito abuso sexual. Provavelmente não teria havido isso se eles soubessem que aquilo que sentiam, aquela reação em seus corpos que presenciavam quando viam um homem que os atraía, se chamava desejo homossexual. A privação de uma informação essencial limita a liberdade. Não saber dar nomes aos sentimentos confina seriamente as pessoas em espaços aprisionados.

A cultura é importante na medida em que abre horizontes para as pessoas. Abre-se um horizonte novo quando se descobre que existe um tipo de conduta que não é aceita. Pode ser homossexualismo, divórcio, preconceito de cor. A cultura abre horizontes - às vezes, apenas pelo fato de alguém começar a manejar um lápis, uma tinta, uma câmera de vídeo, ou seja, aprender uma nova linguagem. É como se alguém estivesse aprendendo inglês ou francês, ou aprendendo a desenhar. Uma nova língua amplia o contato com o mundo. Artes plásticas ensinam também a ver melhor esse mundo.

\section{Criação permanente de novas formas de vida}

A partir do conceito de experiência cultural, acontece a relação da cultura com as outras dimensões da vida humana: cultura e ética, cultura e economia e cultura e política. Isso nos estimula a algumas reflexões.

A principal questão do nosso tempo é a liberdade para a criação de novas formas de vida. É o fato de que os sistemas que defendíamos entraram em crise ao longo do século XX, sobretudo na segunda metade: coisas que eram proibidas se tornaram lícitas em relação ao amor, ao trabalho, ao sexo.

Essas mudanças tornaram obsoletos vários padrões. Mas o importante não é a substituição de um modelo por outro - e sim que, hoje, não se sabe, necessariamente, o que vai ser bom. Porque não é substituindo um padrão proibido por um padrão permitido que se resolve o conflito. Aliás, um novo padrão, se impositivo, apenas cria um novo constrangimento. Por isso, o importante não é a troca de padrões, mas a redução do papel dos padrões.

Isso não é consenso. Vários movimentos, sobretudo os que procuram reverter um processo histórico visto como injusto - e aí incluo grupos com cujas causas simpatizo: feministas, negros, homossexuais, pobres -, tendem às vezes, porém, simplesmente a trocar os sinais. 
Vários movimentos, sobretudo os que procuram

reverter um processo histórico visto como injusto

- e aí incluo grupos com cujas causas simpatizo: feministas, negros, homossexuais, pobres -, tendem às vezes, porém, simplesmente a trocar os sinais. $O$ "politicamente correto", expressão contraditória em si mesma (porque o político é o espaco da pluralidade, dos valores diferentes, que não podem ser medidos pela régua do certo e do errado, do correto e do incorreto), é o exemplo infeliz disso.

O “politicamente correto", expressão contraditória em si mesma (porque o político é o espaço da pluralidade, dos valores diferentes, que não podem ser medidos pela régua do certo e do errado, do correto e do incorreto), é o exemplo infeliz disso.

Uma consequência, que tem levado a vários incômodos, é que certos discursos, historicamente proibidos, se tornam dominantes, enquanto os discursos que eram dominantes passam a ser discriminados. Vejam que em certos casos, ouvindo alguns discursos feministas, se vocês trocarem os sexos ou gêneros (isto é, colocasse homem em vez de mulher, e vice-versa), terão nada mais nada menos do que um velho discurso machista.

Isso não é dominante, mas tem certa frequência, a meu ver preocupante - porque não representa a superação de um padrão obsoleto, e sim apenas uma vingança, uma troca de sinais, uma manutenção no mesmo nível.

Este assunto merece uma curta digressão. Compreende-se que os oprimidos historicamente desejem uma revanche. Entende-se que, para quem foi humilhado, a simples igualdade com o antigo opressor tenha um sabor de injustiça: afinal, ele não vai pagar pelo que fez. Daí que, com certa freqüência, processos revolucionários tenham um elemento de vingança, que porvezes é chamado, impropriamente, de justiça (justiça revolucionária, por exemplo).

Contudo, olhando para o período que começa com a Revolução Francesa e vai até as revoluções de esquerda da segunda metade do século XX, vê-se que essa estratégia não deu certo. Ela geralmente apenas produziu novos problemas. Os países pobres, em que houve revoluções de esquerda que romperam radicalmente com a antiga classe dominante, raras vezes conseguiram avançar no próprio resgate da dívida social. Geralmente, afundaram na ineficiência econômica e acabaram restaurando a desigualdade social e a corrupção.

Ora, se isso vale para os casos de conflitos de classes sociais, vale ainda mais para os casos de conflitos de gênero ou etnia. Porque, a rigor, as classes sociais são figuras que podem nascer e desaparecer ao longo da história. Os gêneros, ou sexos, não . Nem se deseja que etnias desapareçam sem mais. E é por isso que a simples troca de sinais - tornando positivo o que era negativo e inversamente - é insatisfatória. Por isso, a questão não é virar as coisas pelo avesso, mas mudar de patamar. Se não o fizermos, corremos o risco de caminhar para o pior do século que passou.

Nessa mudança de patamar, as pessoas estão tendo de criar constantemente novas formas de vida que valem para umas e não para outras. Nisso, a cultura pode ajudar muito, porque lida com a criação. Quando exercitamos nossa criatividade, quando nos dedicamos a criar - seja desenhando, cantando, filmando etc. -, temos maior facilidade para encontrar saídas para situações que consideramos adversas.

Em 2003, ministrei um curso na Universidade Columbia, em Nova York. Como ele estava no quadro do Instituto de Estudos Latinoamericanos, quis tratar de nossa parte do mundo - embora meu foco de pesquisa seja a filosofia política - mas não queria falar de pobreza, miséria, ditadura, isto é, dos temas usuais. Tratá-los é correr o risco, às vezes, de expor somente nossas mazelas, e de suscitar piedade, ajuda, socorro. Isso às vezes, nem sempre - porque respeito muito quem trabalha esses te- 
Mas, quando a sociedade demanda de nós mais escolhas do que no passado, ela nos interpela eticamente também mais que no passado, e com isso a cultura aumenta em importância. Este é um dos aspectos que nos fez experimentar grandes mudanças com relação à cultura ao longo do século XX.

Até certo momento do século passado, a cultura se constituía num cabedal, num capital, em algo que se acumulava. A pessoa culta, que sabia línguas, que cursara uma faculdade, o médico, o engenheiro, o advogado, aquele que conhecia cultura francesa, dominava Racine e sabia falar longamente a respeito, tinha, porém, várias vezes, um grande problema: com frequência, não produzia qualquer ideia original. 0 que reunia era um extenso conhecimento, uma acumulação.

Ora, a certa altura do século XX, ocorreram mudanças nesse perfil. No Brasil e em São Paulo, foi decisiva nesse sentido a criação da Universidade de São Paulo e, nela, da Faculdade de Filosofia, Ciências e Letras, uma grande faculdade de pesquisa, que transferia o estudo da física, da literatura e da filosofia das mãos dos diletantes para as dos especialistas. Esse foi um dos modos de enunciar que o importante deixava de ser acumular conhecimento, e se tornava necessário gerá-lo, criticá-lo, vivê-lo.

É como se antes tivéssemos um tesouro, no mau sentido do termo: um entesouramento infecundo. É curioso que hoje se fale em capital social, capital cultural, capital humano. Esses termos têm sentido positivo, pelo menos para os que os empregam. São entendidos como instrumentos para melhorar o mundo. Não têm mais o sentido de que estejamos apenas acumulando um cabedal, como um avarento, como alguém que poupa, mas apenas sabe repetir.

Com a cultura não se pode ser avarento. Não se pode entesourá-la. A cultura, temos de compartilhá-la, de utilizá-la para mudar a vida para melhor. E não apenas nossa vida pessoal. Ela nos permite mudar a vida na relação com os outros. Nós vivemos em relação.

\section{Intencionalidade, erro e mentira.}

\section{Vamos refletir sobre a mentira. Posso cometer um erro:}

dois mais dois igual a cinco. Isso é um erro. Porém, se eu for um vendedor e cometer um erro na conta, já não se trata de erro, mas de fraude, mentira (a não ser, claro, que seja involuntário). É diferente. 0 erro não traz em si a má intenção; a fraude e a mentira, sim. Elas só

\section{Porque, quando tenho liberdade para me} questionar, isso também se configura como relação. A cultura permite isso. Permite que a pessoa veja a si mesma com uma amplidão maior, como se fosse de fora, de modo que estabelecemos também uma relação de exterioridade com a intimidade, fazendo, para usar a célebre expressão psicanalítica, que
o eu seja um outro.

existem na relação com o outro. Não há fraude ou mentira sem a relação social. Já o erro pode existir na solidão do indivíduo. Por isso, é importante distinguir erro e mentira.

Dois mais dois igual a cinco. Se responder assim à prova, recebo uma nota ruim. Porém, se for caixa, errando prejudicarei o cliente; por isso é que se vai além do erro. Mentira ou fraude têm a intenção de enganar o outro. É na relação com o outro que fazemos o mundo meIhorar ou piorar. Geralmente, melhoramos ou pioramos o mundo em relação com outra pessoa; às vezes, na própria relação com a gente mesmo; mas esse é um ponto mais complexo, que abordarei apenas de passagem.

Porque, quando tenho liberdade para me questionar, isso também se configura como relação. A cultura permite isso. Permite que a pessoa veja a si mesma com uma amplidão maior, como se fosse de fora, de modo que estabelecemos também uma relação de exterioridade com a intimidade, fazendo, para usar a célebre expressão psicanalítica, que o eu seja um outro. Essa relação pela qual a pessoa questiona a si mesma permite pôr em xeque as identidades recebidas. 
Nossa televisão assumiu, sobretudo nas novelas, faz décadas, alguns valores importantes: por exemplo, a igualdade dos sexos, o não preconceito contra o homossexualismo. Foi mais difícil passar o não preconceito contra as lésbicas: mas elas, hoje, conseguem viver até o fim de uma novela sem morrer em acidente ou em algo do gênero .

A TV também levou para as pessoas de lugares afastados dos grandes centros uma série de liberdades que antes não tinham. A novela pode fazer merchandising; sempre vai pregar o consumismo; ela passa a ideia de que a ascensão social é a saída. Não aprovo nada disso, mas reconheço que ela também transmite, numa linguagem de fácil compreensão para milhões de pessoas, um discurso contra certos preconceitos. Isso foi e continua sendo positivo.

\section{Democracia como sentimento}

\section{A relação da cultura com a democracia é curiosa porque é} uma relação de mão dupla. Por um lado, para que a população tenha acesso à cultura, é preciso que haja democracia. A cultura é um dos principais alimentos da democracia. Pessoas incultas terão maiores dificuldades para encontrar seus caminhos, tanto políticos como pessoais. A cultura faz crescer as pessoas, como sustentei acima.

Ao mesmo tempo, enfrentamos um problema na democracia. Ela cresceu muito nos últimos duzentos anos. Hoje, temos talvez metade da população do mundo vivendo em países nos quais podem se expressar, se organizar, votar, escolher sua profissão e seu cônjuge. Há muito mais liberdade que no passado. Nunca houve tanta gente com tanta liberdade quanto hoje no mundo. Ainda há muito por fazer, mas o avanço foi significativo.

Contudo, se a democracia é uma forma de governo com muitas qualidades, nós a vivemos mais como um regime racional do que como um registro afetivo de significações. Em outras palavras, uma cultura democrática ainda não se consolidou.

Aqui estou pensando em cultura no sentido antropológico e não no que usei acima. No que afirmei antes, pensei em cultura no sentido mais corrente: o das artes, da literatura, do conhecimento que forma as pessoas. Agora, estou falando em cultura na acepção que the dá a antropologia, isto é, como um conjunto de significações que são atribuídas aos atos humanos. 0 mesmo ato pode ter significados diferentes.
Assim, a questão não se resume em ampliar a participação cultural na democracia. Aliás, nem é essa a questão principal, a meu ver, e sim: será que a democracia é uma cultura? Será que existe uma cultura democrática no sentido de a gente gostar da democracia, do respeito ao outro, da diferenca, gostar da divergência por gostar e não apenas porque racionalmente ouvimos ou dizemos que tenho que respeitar o outro?

O caso mais engraçado é o do gesto com a cabeça que para nós significa não, e que em várias culturas quer dizer sim. Mas, além disso, há significações mais profundas: por exemplo, quando a mesma atitude que numa cultura é entendida como sinal de independência, autonomia, respeito ao outro, em outra se compreende como indiferença, frieza, descaso.

Ora, no caso da democracia e da república e dos regimes mais abertos, politicamente falando, eles são regimes que - ainda - estão em conflito com a formação afetiva que tivemos. Porque nossa formação afetiva, por milênios, aconteceu de maneira predominantemente autoritária, o que vale tanto para a política quanto para a dimensão pessoal, em que, por exemplo, avulta o machismo. Veja-se, no Brasil, o uso do coração como emblema, por dois políticos conservadores, um na Bahia, outro em São Paulo.

Assim, a questão não se resume em ampliar a participação cultural na democracia. Aliás, nem é essa a questão principal, a meu ver, e sim: será que a democracia é uma cultura? Será que existe uma cultura democrática 
no sentido de a gente gostar da democracia, do respeito ao outro, da diferença, gostar da divergência por gostar e não apenas porque racionalmente ouvimos ou dizemos que tenho que respeitar o outro?

Se dizemos de uma cultura que é autoritária - por exemplo, a dos talibans e, antes deles, as de várias etnias e seitas que discriminam a mulher -, por que não dizer de uma cultura, talvez ainda por vir, que é democrática?

Certamente isso não é fácil e provavelmente precisaremos de uma mudança muito grande para aceitar que nos enriquecemos com a divergência e para criar uma condição pela qual a democracia se torne uma cultura.

A democracia se enfraquece hoje, ou melhor, a democracia ainda não desenvolve todos os seus potenciais, porque nela o elemento de racionalidade, de razão, não foi superado pelo de vivência, de espontaneidade, de cultura, em suma. Se e quando conseguirmos isso, teremos dado um salto. Exemplo nessa direção são as escolas que ensinam as crianças a respeitar seus coleguinhas, a brincar de maneira mais solidária que competitiva. As pessoas assim aprendem a significar seus atos de uma maneira que não é autoritária.

\section{É difícil planejar resultados na cultura}

\section{Ninguém discorda de que a cultura - entendida como o} universo de uma produção de qualidade que experimentamos de modo a ampliar nossa compreensão do mundo e nosso fazer o mundo - é importante para a formação humana. Por que então a cultura é tão desvalorizada? O que faz da cultura essa coisa poderosa e complexa e, ao mesmo tempo, renegada e diluída? E mais, a cultura pode ser tudo, em um determinado momento: a maneira de sentir, de pensar, de vestir, de amar.

Ao definir suas políticas públicas, os governantes falam em saúde, educação, transporte, trabalho. Quase nunca em cultura.

Como fui diretor da Capes e também pertenci ao conselho do CNPq, acompanhei tanto o Ministério de Ciência e Tecnologia quanto as políticas de educação e de financiamento. Os pedidos que vêm ao CNPq e que passam pelo crivo de qualidade - a chamada "demanda qualificada" - são atendidos em $70 \%$, talvez $80 \%$.

0 orçamento do Ministério da Cultura é bem menor do que o de Ciência e Tecnologia; deve ser talvez um terço dele. Lembro-me de que, quando estive no conselho do CNPq, em meados da década de 1990, o MCT recebia 0,35\% do orçamento, o que já era abaixo da margem de erro da elaboração do orçamento (margem de erro que seria de $0,5 \%$ ); e o da Cultura, 0,05\%. Como os militares recebiam $30 \%$ do orçamento, calculei: uma tarde dos ministérios militares seria um ano do da Cultura.

Por que isso, melhor dizendo, por que a comunidade científica tem mais êxito em suas demandas do que a cultural? Primeiro, a comunidade científica é bem organizada; segundo, a comunidade cultural é enorme, difusa, desorganizada e permeia várias classes sociais.

Com a cultura, não se obtêm resultados tangíveis no curto prazo. Nas ciências, sobretudo as exatas e biológicas, conseguimos resultados mais visíveis. Na cultura, os parâmetros são outros. Um projeto pode custar muito mais caro que outro e ter muito menos impacto. É muito difícil elaborar esses conceitos. Essa explicação procura levar em conta as políticas públicas e os atores que conduzem projetos, quer científicos, quer culturais.

Há também um fenômeno perverso: por que as pessoas em geral, as que elegem o governo, não dão importância à cultura? Será que a cultura não reúne coisas sérias? Ou as coisas sérias seriam aquelas apontadas pelos cinco dedos da mão do então candidato a presidente Fernando Henrique Cardoso, em 94: saúde, habitação, emprego, transporte e segurança? Aparentemente, essas cinco coisas são seriíssimas, são do bem. A cultura não está aí. Não é que seja algo mau. Simplesmente, não aparece.

Há talvez certa prevenção contra a cultura. Cultura não costuma aparecer como algo relevante, como primeira, segunda ou terceira necessidade social. Talvez isso tenha a ver um pouco com a natureza mesmo da cultura, pelo fato de ela estar muito ligada à liberdade. Ela também não é algo no qual se investe e se tenha a certeza de determinado resultado.

Não é a mesma coisa que plantar, por exemplo: os proprietários rurais semeiam, adubam, rezam para que chova e faça sol na época certa. Tudo correndo bem, os resultados esperados são conseguidos.

E na cultura? Ninguém sabe como vai ser o resultado. Não se sabe se a obra vai dar certo ou não, se o público vai gostar, se vai ter impacto. Produzem-se obras, realizam projetos que costumam ter resultados opostos aos previstos.

Há a história famosa de um índio que nunca tinha saído de sua aldeia e que foi levado a Nova York. A coisa 
Ora, no caso da cultura

(e da educacão), o céu é o limite. Nunca nos podemos saciar. Sempre pode haver mais. É nesse sentido que, enquanto uma política de saúde desenha limites, metas, finais, uma de cultura não tem como chegar a um máximo, a uma completude. É por isso que mesmo o que na cultura é necessário está se ligando a uma crítica do conceito de necessidade.

que mais o impressionou foram as lâmpadas redondas em cima dos corrimões, na escadaria do hotel. Não foram carros, arranha-céus, roupas e luzes. A cultura tem muito imprevisto e talvez queiramos, hoje, lidar com o social de uma maneira muito previsível.

Não é casual que o Ministério do Planejamento seja tão importante. Fala-se o tempo todo em planejamento. As pessoas são instadas a planejar tudo: gastos, educação e até a própria vida. Avanços na gestão pública se devem a bases de dados, de acesso fácil, pelas quais ficamos sabendo o que se propôs e o que se executou.

Na cultura, porém, temos diante de nós um espaço de liberdade, onde o risco é muito grande. A cultura, entendida como aquele conjunto de criações de excelência que nos abrem janelas para o infinito, é importantíssima, mas não suporta tanto planejamento. Se não houver certa imprevisibilidade, advinda da liberdade para experimentar e sentir, ela não dá certo. Em outras palavras, ela exige correr um risco muito grande.

Se quiser dizer de outro modo: talvez FHC tivesse razão em não incluir, nos dedos de sua mão, a cultura. Isso porque se tratava do que é necessário; ora, a cultura sai do reino da necessidade e compõe o da liberdade. Se assim for, deveríamos parar de mencionar a ne- cessidade da cultura e entender que, pelo conceito usual de necessidade, ela é rigorosamente desnecessária e mesmo anti-necessária.

Essas palavras podem soar demagógicas. Não é minha intenção. Por um lado, a cultura tem a ver com o inútil; ela rompe com o útil e, portanto, também com qualquer rol de necessidades, ou de gêneros de primeira necessidade. Por outro, é evidente que, em tudo o que afirmei, está presente a idéia de que a cultura seja necessária, no sentido de que é importante para nossa liberdade e para a qualidade de nossa vida.

Mas o ponto em que essa aparente contradição se resolve fica claro se compararmos a cultura (e a educação, penso eu) com a saúde. Sabemos todos o que é estar doente e o que é ter saúde. Este conhecimento é quase intuitivo. Por isso, sei se o atendimento hospitalar é bom ou mau. Posso ignorar os detalhes, mas em linhas gerais sei fazer a distinção entre o bom e o mau atendimento.

Ora, no caso da cultura (e da educação), o céu é o limite. Nunca nos podemos saciar. Sempre pode haver mais. É nesse sentido que, enquanto uma política de saúde desenha limites, metas, finais, uma de cultura não tem como chegar a um máximo, a uma completude. É por isso que mesmo o que na cultura é necessário está se ligando a uma crítica do conceito de necessidade.

\section{Será necessária uma economia da cultura?}

\section{Qual é a idéia, o mote das propostas do Ministério da}

Cultura? Reconhecer e apoiar a diversidade, as formas diferentes de expressão, de transmissão. Ao mesmo tempo, por serem programas de governo, há exigências a serem cumpridas: devem ter bom desempenho, quantitativa e qualitativamente. Seus promotores devem saber gerenciar verbas, preencher planilhas. Daí, decorrem necessidades em termos de planejamento e gestão; daí, decorre a necessidade de uma economia da cultura.

Pensando na sociedade como um todo, podemos refletir sobre três aspectos da cultura:

- a criação - lado que envolve mais risco, mais novidade, mais chance de dar certo, de dar errado;

- a preservação - que é o lado que envolve patrimônio, a garantia de que um filme não vai desaparecer, de que um livro não vai ser comido pelas traças e tudo o mais (bibliotecas, museus são muito voltados a isso, pelo menos em princípio); 
- a difusão - que é a razão principal de ser de uma biblioteca, de um museu, de um festival, das salas de cinema.

A criação pode custar caro. Pode ter poucos beneficiários dos recursos. Pode também dar errado. Esses são problemas mais ou menos inevitáveis. Criar geralmente - embora nem sempre - é mais caro que preservar. Daí, também, que as pessoas que recebam recursos para criar sejam em pequeno número.

Isso cria conflitos internos, entre quem ganhou e quem não recebeu recursos, e também externos - entre a criação e as duas outras áreas que mencionei. Além disso, como não se sabe se vai dar certo, aqui sempre estamos mais perto da aposta que do investimento.

Finalmente, há certos setores da criação artística que são mais caros que outros. A música clássica não é barata, e provavelmente por isso as nossas melhores orquestras tiveram duração limitada no tempo. Talvez por isso, também, a Orquestra Sinfônica do Estado de São Paulo - Osesp, depois de criada com enorme sucesso, mas a alto preço, passe, desde 2008 , por uma crise, que teve como sinal mais visível a demissão do seu recriador: 0 custo de certas atividades artísticas é elevado a ponto de somente uma decisão política - sempre arriscada sustentá-la .

A Espanha surpreende: está produzindo quase 200 filmes por ano. Há inúmeras linhas de financiamento para o cinema. Contudo, há películas que não foram vistas nem por cem pessoas. Então há algo sobrando, há um excesso. 0 que se vai fazer? Se não se aplicar, vai sobrar dinheiro. É uma coisa engraçada, não é? Não deveria sobrar dinheiro na cultura. Provavelmente ele está indo na direção errada. Na Espanha, é possível que áreas da criação cultural estejam recebendo mais do que precisam, e outras, menos. Mas meu ponto é: na cultura, nunca sobra dinheiro. Se está sobrando, é num setor; sempre se pode destinar esse dinheiro para outro rumo, em que ele faça uma diferença.

A difusão é o mais óbvio numa política cultural. Tende, se não a ser a mais barata, a ter a relação menos problemática entre custo e benefício. 0 investimento nela é relativamente baixo, em especial naquilo que deriva do que foi chamado a reprodução mecânica e que, hoje, foi bem além do mecânico - eu preferiria falar em reprodução digital. O seu risco é cair para o entretenimento. A sua potencialidade é fazer que os espectadores ou usuários se tornem, a seu modo, criadores. 
O exemplo, que citei, da menina que assistia à Flauta Mágica, e vinha a conhecer um novo mundo a partir dessa ópera, mostra como ficam fluidas as fronteiras entre a criação e a recepção: esta, como insistiu a melhor teoria do século XX, será tanto melhor quanto mais criativa for. Por isso mesmo, aquele ecletismo que antes critiquei dos homens cultos que eram médicos ou engenheiros e, além disso, conheciam Racine mas não o estudavam passa a ser uma forma inferior de recepção, pouco diferente, em última análise, do entretenimento.

É claro que há diferença entre essa pessoa culta que ouve música erudita e alguém que vai a um multiplexver o último blockbuster; mas têm em comum, ambos, ficarem muito perto da passividade, não se alçarem à criação. Mesmo quando se quer que a difusão ajude a aumentar a criatividade. Essa linha de políticas culturais está mais aberta a uma economia e a um planejamento do que à criação propriamente dita. É, finalmente, a área que dá maior retorno de público e, portanto, político.

A preservação, finalmente, é área que pode ser cara, embora geralmente seja mais barata que a criação; é a área que não é imediatamente visível e por isso não tem a popularidade que pode concorrer em favor da difusão e da própria criação; e é área que requer planejamento, administração, prestação de contas.

Um ponto presente nas três áreas, mas diferente, é o das opções e de seu custo. Escolher o que difundir e o que criar (ou o que incentivar para criar, porque nem toda criação depende de verbas) é uma questão de prioridade. Não é uma questão de exclusão. No caso da preservação, pode ser questão de vida ou morte.

Se decidirmos preservar tal obra e não outra, pode ser porque estejamos condenando a segunda à morte. Na verdade, há tal superávit de obras em relação à memória que delas se pode ter, que parte substancial delas sucumbe ao tempo. Não falo em termos físicos, em termos de serem destruídas ou de se deteriorarem: simplesmente, são esquecidas. Mas, por isso mesmo, e na mesma linha, o que se vai conservar ou não é uma escoIha - aqui, mais consciente - de memória.

Por exemplo, se sabemos que Eduard Strauss, irmão menos conhecido de Johann Strauss Filho, compôs centenas de valsas e outras músicas que hoje mal são tocadas, nem por isso suas partituras têm de desaparecer; mas, quando pensamos em algo cujo suporte físico faz parte da essência da obra, a decisão de preservá-la ou não já diz respeito a sua sobrevivência ou morte.
Eis um tipo de escolha que não parece tão grave quando seu alvo é a criação ou difusão, porque, na preservação, se trata do passado, de um passado ao qual vai se dar futuro - ou negá-lo. Em outras palavras, deixar de criar (ou difundir) uma obra é uma coisa; matar uma que existe ou existiu é outra. Há assim certa tragicidade na preservação, ou nas escolhas que em seu nome se fazem.

\section{Estamos aprendendo a dar valor à cultura}

\section{Acredito que o setor que trabalha com cultura tenha de}

se organizar um pouco mais. Faz parte da criação cultural ser um pouco desorganizada. Mas, no nosso caso, essa desorganização é grande e os gestores acabam defendendo pouco os interesses que são comuns. Os profissionais de ciência e tecnologia sabem defender melhor seus interesses e conseguem melhores resultados nas suas demandas ao governo por financiamento. Já a cultura tem orçamento menor e demanda bem maior.

Há um ponto adicional. Desde o governo FHC, a realidade que se está criando na cultura dá certa ênfase à ideia de economia e de planejamento econômico. A própria cultura começa a ser levada mais a sério quando se diz que pode haver uma economia da cultura. Os gestores têm falado cada vez mais nela. Aliás, quando fui diretor da Capes, tentei formatar um mestrado profissional em gestão de cultura. Foi esse um dos pontos principais do seminário que organizei em março-abril de 2005 sobre o tema Para além da academia, que tratou de mestrados profissionais. O MinC ficou muito interessado numa conversa preliminar, bem como a secretaria estadual de São Paulo; mas nada se desenvolveu.

Segundo o próprio MinC, a produção de música independente no Brasil não aumenta ainda mais por falta de gestão. É grande a área de produção independente, mas falta gestão. Esse é um problema sério.

Por outro lado, a cultura é altamente libertadora. Isso nem sempre facilita a sua organização. Ela sempre tem em seu cerne alguma violação da seriedade. E a política é muito séria, quase horrível. Vejam os reitores. Em qualquer universidade, a maior parte dos professores está vestida como gente normal, com roupa normal. Mas você vai à reitoria e encontra as pessoas de terno e gravata. 0 próprio reitor, quando vai encontrar outros reitores, o ministro e pessoas com poder, vai sempre de terno e gravata. Sua comunidade não usa esses trajes. 
Como ele representa assim a comunidade a que pertence? Sempre achei isso estranho.

Acredito que a cultura pode ajudar muito o Brasil a construir uma sociedade melhor. Primeiro, porque temos um componente cultural muito forte na nossa sociedade: nossa música popular, nossas novelas. São duas formas de arte em que o Brasil adquiriu uma excelência superior à maior parte dos países do mundo. Em outras artes, nós temos um nível também muito bom, mas nessas duas, que são até mais para um público popular, o Brasil conseguiu uma diferença grande.

E nós temos também recuperado muitas formas e manifestações culturais de povoações que foram discriminadas; estamos valorizando também aspectos que antigamente não eram tão valorizados. A própria culinária está sendo mais e mais reconhecida. Acho que há uma possibilidade de o Brasil investir muito nisso e assim ter uma sociedade mais equilibrada, mais justa e também uma sociedade mais criativa.

O futuro vai ter muito a ver com justiça social e criatividade. E justiça social se torna necessária, porque as pessoas pobres não estão mais aceitando a pobreza da maneira subserviente como aceitavam antes. Elas se revoltam, e isso é bom. Mesmo que, às vezes, a revolta machuque, mas o princípio disso é bom.

A outra coisa que é muito nova no mundo é a criatividade. Como nós não temos mais a vida como um pacote, quer dizer, você não tem mais um pacote de vida programada - sou um homem de classe média alta, católico, vou ser engenheiro, vou me casar e ter filhos - independentemente de ser, por exemplo, homossexual, ateu, ou o que seja e não gostar dessa profissão.

Mas como a nossa vida já não está prevista pelos nossos pais, podemos estabelecer outras condições, realizar o que é importante para nós no amor, no trabalho, nos relacionamentos, no lazer.

Cada um de nós vai compor isso mais ou menos a seu gosto e dentro de suas possibilidades. Nossa época exige muito mais criatividade do que as anteriores. Tudo o que consiga ligar criatividade, que é a praia da cultura, com justiça social e, portanto, redução da desigualdade, redução do sofrimento humano, é algo que tem e precisa ter futuro.

Precisamos agir seriamente por isso.

\section{NOTAS}

1 Há uma tendência de pensadores anglo-saxônicos a usar "gênero", mais do que "sexo", para enfatizar o caráter não biológico, mas cultural, do que é masculino e feminino. Lembro que, na tradição continental européia, "sexo" não é uma determinação puramente biológica. Para se valorizar gênero contra sexo, é preciso primeiro reduzir a polissemia da própria palavra sexo.

2 Para detalhes sobre este curso, bem como os trabalhos dos alunos, ver http://renatojanine.pro.br/LEstrangeira/freedom.html.

3 Questão que tratei em meu livro $O$ afeto autoritário - televisão, ética, democracia (São Paulo: Ateliê editorial, 2005). A entrevista do programa Roda Viva a respeito pode ser lida em http://www.rodaviva.fapesp.br/materia/113/ entrevistados/renato_janine_ribeiro_2005.htm.

4 Ver John Neschling, Música mundana, 2009. 